\title{
RISKS AND BENEFITS OF HORMONE REPLACEMENT THERAPY IN OLDER MEN
}

\author{
Fábio Firmbach Pasqualotto, Antônio Marmo Lucon, Jorge Hallak, Eleonora \\ Bedin Pasqualotto and Sami Arap
}

PASQUALOTTO FF et al. - Risks and benefits of hormone replacement therapy in older men. Rev. Hosp. Clin. Fac. Med. S.

Paulo 59(1):32-38, 2004.

The use of testosterone in older men, known as male hormonal replacement therapy or androgen replacement therapy, has become of increasing interest to both the medical and lay communities over the past decade. Even though the knowledge of the potential benefits and risks of male Androgen Replacement Therapy has increased dramatically, there is still much that needs to be determined. Although there are a number of potential benefits of male Androgen Replacement Therapy and data concerning clinical effects of such replacement have accumulated, as yet there have not been any large multicenter randomized controlled trials of this therapy. It is the purpose of this article to review what is currently known about the possible risks and benefits of male Androgen Replacement Therapy by discussing the clinical trials to date.

DESCRIPTORS: Testosterone. Androgen. Hormones. Elderly. Replacement.

Blood levels of testosterone decline with age in most men, even in those who are healthy, and this decline probably begins around the age of 30 . The rate of decline varies greatly between individuals, and most of the data are to be found in studies of Caucasian men; both cross-sectional and longitudinal studies confirm this decline ${ }^{1-}$ ${ }^{3}$. Decreased production of testosterone by the testes is the main reason for the lower testosterone levels in older men ${ }^{4}$. From a clinical standpoint, the pertinent question is whether this decline in testosterone is significant enough for many older men to consider testosterone replacement therapy.

In the younger adult hypogonadal male, there are a number of detrimental changes in the organs and their functions accompanying the normal aging process that might be positively influenced by Hormone Replacement Therapy (HRT) (Table 1) ${ }^{2-15}$. Among these age-related changes are a decrease in muscle tissue mass and a decline in muscle strength ${ }^{5,6}$, an increase in body fat, a decline in bone mass, and an increased incidence of osteoporosis and minimal trauma fractures $^{7-9}$, as well as a decline in the quality and quantity of sexual thoughts and enjoyment ${ }^{10}$. In older men, these changes may be caused by chronic illness, medications, and other hormone deficiencies, but it is also possible that many of these could be exacerbated by a relative testosterone deficiency. It is important to note here that in the younger adult hypogonadal male, treatment with androgens is absolutely justifiable, not being a matter of ques-

\footnotetext{
From the Department of Urology, Hospital das Clínicas, Faculty of Medicine, University of São Paulo - São Paulo/SP, Brazil. Received for publication on May 19, 2003.
}

tion. The question is whether hormones in older men should be replaced or whether hormones in men with age-related gonadal deficiency should be replaced.

Although not all of the possible benefits and risks of HRT have been established, on the basis of our present knowledge of the action of testosterone, the effects of replacement therapy in young hypogonadal adult men, and the outcomes of clinical experience and studies, a list of such benefits and risks can be compiled (Table 2) ${ }^{2-40}$.

Furthermore, at the present time, there is no agreement as to which hormonal or clinical criteria should be used to decide which older men might be candidates for HRT, although there have been several consensus groups convened to establish such criteria. There are a number of reasons for this failure of consensus, including: 1) lack of simple measurements or findings 
Table 1 - Changes in some androgen target organs with normal aging and with Hormonal Replacement Therapy (HRT) in young hypogonadal men.

\begin{tabular}{lcc}
\hline Target organ & $\begin{array}{c}\text { Changes seen } \\
\text { with aging }\end{array}$ & $\begin{array}{c}\text { Changes seen with Hormonal } \\
\text { Replacement Therapy in } \\
\text { hypogonadal men }\end{array}$ \\
\hline Muscle mass & $\downarrow$ & $\uparrow$ \\
Muscle strength & $\downarrow$ & $\uparrow$ \\
Fat mass & $\uparrow$ & $\downarrow$ \\
Bone mineral density & $\downarrow$ & $\uparrow$ \\
Libido & $\downarrow$ & $\uparrow$ \\
Sense of well-being / improved mood & $\downarrow, \leftrightarrow$ & $\uparrow$ \\
\hline
\end{tabular}

Table 2 - Potential benefits and risks of Hormonal Replacement Therapy in older men.

\begin{tabular}{ll}
\hline Benefits & Risks \\
\hline Preserve/Improve bone mass and prevent fractures & Retain fluid \\
Increase muscle mass and strength & Precipitate or worsen sleep apnea \\
Improve physical functions & Develop gynecomastia \\
Decrease cardiovascular disease risk & Produce polycythemia \\
Improve libido & Increase cardiovascular benign risk \\
Improve well-being and mood & Hasten development of benign or \\
& malignant prostate disease \\
Improve aspects of cognition & \\
\hline
\end{tabular}

that would classify an older man as being "testosterone deficient"; 2) disagreement as to which hormonal measure or measures are the most appropriate to use in screening older men for testosterone deficiency; 3) little or no data regarding organ-specific testosterone dose response in the older man, and 4) absence of large prospective randomized male HRT clinical trials evaluating clinical outcomes. In addition, it has not yet been established whether the mode or dose of testosterone used for replacement therapy will affect outcomes. These issues must be kept in mind when evaluating the current data on benefits and risks of testosterone replacement in older men.

\section{CARDIOVASCULAR EFFECTS}

As noted in Table 2, the potential effect of HRT on cardiovascular disease is listed both in the benefits and risks columns. In the past, androgens have been classified as a potential adverse factor with regard to cardiovas- cular disease because of the fact that men are more likely to develop cardiovascular disease than women of the same age. However, this may just mean that women are better protected from cardiovascular disease. A historical review has demonstrated that the life expectancy of castrated male opera singers was similar to that of intact male singers ${ }^{16}$. Studies in young men have demonstrated that testosterone causes a lowering in HDL-cholesterol, and in some cases, an increase in LDL-cholesterol. On the other hand, epidemiological studies have reported that men with lower serum testosterone levels are more prone to heart disease ${ }^{17}$. Short-term studies have shown that in men with known cardiovascular disease who are given intravenous testosterone, ischemia takes longer to develop during exercise testing ${ }^{18}$. Furthermore, testosterone infused into coronary arteries seems to have a vasodilatory effect ${ }^{19}$. Testosterone has been shown to increase fibrinolysis and lower triglyceride levels.
Although HRT may cause a temporary state of fluid retention, as yet no reported cases of exacerbation of hypertension or congestive heart failure in older men during such therapy have occurred. A decline in lipoprotein(a) levels during HRT in older men has been suggested ${ }^{20}$.

\section{LIBIDO, WELL-BEING, AND MOOD}

Testosterone administration in young hypogonadal men has been shown to increase libido and the frequency of sexual activity ${ }^{21}$. Some studies have shown that testosterone positively affects well-being and mood in hypogonadal young men ${ }^{21,22}$. Lower serum bioavailable testosterone levels were found to be associated with depressed mood in a large cross-sectional study of older men ${ }^{23}$.

The study of testosterone in depression was prompted by the observation that in castrates and hypogonadal men treated with androgen, the incidence of depressed mood and emotional instability decreased. In comparison to healthy controls, depressed patients had $30 \%$ lower levels of total and free testosterone, while estradiol showed an increase of about $50 \%$. Although some data suggested a dysfunction of the hypothalamo-pituitary-gonadal axis, the majority of researchers concluded that there appears to be no major dysregulation of the axis activity in male endogenous depressives, even if dysregulation might be related to the reduced energy levels and sexual appetite occurring in many depressive men ${ }^{21-}$ ${ }^{25}$. Studies in older men with low libido have generally reported an improvement in libido with testosterone therapy ${ }^{24,25}$. Several studies also have evaluated the effect of HRT on mood in a blind placebo-controlled manner and have demonstrated a positive impact $^{26-28}$. 


\section{COGNITIVE FUNCTION}

The relationship between testosterone and cognitive function is not clear due to a paucity of data, the many different cognitive processes that can and have been assessed, and the timing of androgen exposure in terms of the subjects' ages. In one published study on HRT in older men, there was no change in tested memory during testosterone treatment ${ }^{29}$.

\section{SLEEP APNEA}

Testosterone appears to play a role in the pathogenesis of obstructive sleep apnea, a disease particularly prevalent in middle-aged and older men. Although the incidence of HRTinduced sleep apnea may not be high, physicians should be sensitive to this potential problem and evaluate for sleep apnea by case history prior to the initiation of HRT. Testosterone therapy can worsen sleep apnea in some hypogonadal men, and the treatment of sleep apnea may raise low serum testosterone levels ${ }^{30,31}$. Although the incidence of testosterone-induced sleep apnea is unknown, in a recent study evaluating 54 older men on testosterone for 3 years, no increase in apneic or hypoapneic episodes during sleep while on therapy was demonstrated ${ }^{32}$.

\section{GYNECOMASTIA}

Tender breasts and gynecomastia occur in a small proportion of older men on $\mathrm{HRT}^{11-15}$. A relatively greater percentage increase in serum estrogen levels as compared to serum testosterone levels may contribute to the changes in the breasts. While the incidence of gynecomastia in patients with advanced prostate cancer treated with estrogens might be reduced with local radiotherapy performed before the treatment, this adverse effect can often be overcome with a downward adjustment in the testosterone dose.

\section{POLYCYTHEMIA}

Androgens have been shown to stimulate red blood stem cells and consequently the production of erythropoietin. Even though the coexistence of sleep apnea and elevated body mass index may contribute to the development of polycythemia, this did not occur in many of the men studied ${ }^{32-37}$. Hormonal replacement therapy in older men can often result in a significant increase in red blood cell mass and hemoglobin levels. The increases reported are much larger than those seen when young hypogonadal men are given testosterone replacement. Occasionally, significant polycythemia may result in calling either for reconsideration of the therapy or a decrease in testosterone dose. The pattern of testosterone replacement may affect the magnitude of the change in red blood cell mass. Those methods that give a more uniform level of testosterone within a physiological range throughout the dosing period demonstrate a smaller increase in red cell mass (Table 3).

Table 3 - Hemoglobin and hematocrit (Hct) changes in older men on testosterone (TE) replacement therapy.

\begin{tabular}{lll}
\hline Treatment regimen & $\begin{array}{l}\text { Hemoglobin mean } \\
\% \text { change }\end{array}$ & $\begin{array}{l}\text { \% Men developing } \\
\text { Hct }>52 \%\end{array}$ \\
\hline $300 \mathrm{mg} / 3$ weeks & 20 & 60 \\
$200 \mathrm{mg} / 2$ weeks (average) & 5 to $12(9)$ & $1524-30(26)$ \\
$100 \mathrm{mg} /$ week (average) & 5 to $12(8)$ & $15(15)$ \\
Scrotal patch & 2 to 6 & $0-6$ \\
\hline
\end{tabular}

\section{PROSTATE}

Androgens are involved in the growth of both benign prostate nodule and prostate carcinoma, although whether they play a major role in the initiation of either disease is unclear. Whether male HRT will increase the risk of developing clinically significant prostate disease in men without established prostate cancer or with few or no symptoms of urinary outlet obstruction due to an enlarged prostate is a different question and one for which no solid data are available $e^{4,38-40}$. Androgen deprivation can cause regression in both these prostate diseases, and the presence or history of prostate cancer is an absolute contraindication for the initiation of HRT.

Of the studies reporting PSA values, most reported no increase with testosterone treatment. Of the studies that did show a statistically significant increase in PSA, the PSA varied from $0.41 \mathrm{ng} /$ $\mathrm{mL}$ to $0.84 \mathrm{ng} / \mathrm{mL}^{1,3,4,10,13,39,40}$. Also, the PSA velocity varied from $0.23 \mathrm{ng} / \mathrm{mL} /$ year to $0.52 \mathrm{ng} / \mathrm{mL} /$ year, well within the normal range of accepted yearly change $(<0.75 \mathrm{ng} / \mathrm{mL} /$ year) for men not on testosterone ${ }^{1,3,4,39,40}$. There has been no reported increase in the incidence of prostate cancer in any HRT trials. In none of the studies reporting on testosterone therapy that evaluated parameters such as prostate size, prostate symptom score (IPSS), urine flow rates, and urinary residual volumes was any change in these parameters noted ${ }^{1,4,29}$.

While these data on testosterone therapy and the prostate are encouraging with regard to the risk of such therapy in the short term, the long-term effects on the prostate of HRT are still unknown. Appropriate pretreatment screening for prostate cancer or significantly symptomatic benign disease prior to initiation of HRT, as well as the regular monitoring for development of such disease during therapy, are warranted. 


\section{EFFECTS ON BONE}

Hypogonadism is associated with a reduction in bone mass and is considered to be the cause of male osteoporosis $^{7}$. Men who are physically or chemically castrated in adult life demonstrate significant declines in bone mineral density, while elderly men who are hypogonadal are at increased risk for minimal trauma hip fracture. Because male osteoporotic fractures are becoming a more prevalent problem as men live to older ages, if HRT were to prevent or increase bone mineral density in older men and, in turn, lead to a decrease in fracture number, this would have significant clinical impact. Studies of testosterone replacement in young to middle-aged hypogonadal adult men have generally demonstrated an increase in bone mineral density with therapy ${ }^{8,9,41,42}$.

There have been at least 3 peer reviewed articles that have evaluated the effectiveness of testosterone replacement on bone mineral density in older men with relative "testosterone deficiency" ${ }_{5,6,32}$. The findings of these studies, which have ranged in duration of testosterone use from 6 to 60 months, have generally shown an increase in lumbar spine bone mineral density, although in at least 1 study, this oc- curred only in those men with the lowest baseline testosterone ${ }^{32}$. Less than half of the studies that evaluated bone mineral density at other sites showed an increase at those sites ${ }^{5-9,32,41,42}$. Because testosterone is converted to estradiol in vivo, and because older men receiving HRT often show a proportional increase in serum estradiol levels, it is unclear whether the effect of testosterone therapy on bone is a direct result of testosterone or a result of increased estradiol levels, or both. There are still no data available on the effect of HRT on fracture incidence.

\section{BODY COMPOSITION, STRENGTH,AND FUNCTION}

Normal male aging is accompanied by a decrease in muscle mass, a decline in strength, and an increase in upper and central body fat. Physiological replacement of testosterone in hypogonadal young adult men or supraphysiological treatment of eugonadal men may result in increases in lean body mass, muscle size, and strength (Table 4) $)^{5,6,43-45}$.

The magnitude of the changes in muscle are similar for the older men and the young hypogonadal men, but less than the changes seen in eugonadal men given additional testosterone ${ }^{46}$.

Table 4 - Effect of testosterone replacement therapy in older men on body composition and strength. Data are given as trend and mean percentage changes.

\begin{tabular}{|c|c|c|c|c|c|}
\hline Study & $\mathrm{n}$ & $\begin{array}{l}\text { Length of treatment } \\
\text { (months) }\end{array}$ & Body fat & Lean mass & Strength \\
\hline 10 & 8 & 3 & $\leftrightarrow$ & & $\uparrow$ (grip) \\
\hline 26 & 13 & 3 & $\leftrightarrow$ & $\uparrow(3.2 \%)$ & $\leftrightarrow$ (grip) \\
\hline 27 & 31 & 9 & $\downarrow 6.4 \%)$ & $\leftrightarrow$ & - \\
\hline 28 & 6 & 1 & - & - & $\uparrow(\mathrm{LE})$ \\
\hline 29 & 17 & 12 & $\leftrightarrow$ & - & $\uparrow$ (grip) \\
\hline 32 & 54 & 36 & $\downarrow(14 \%)$ & $\uparrow(3.8 \%)$ & $\leftrightarrow$ (LE, grip) \\
\hline 35 & 9 & 2 & - & - & $\uparrow$ (grip) \\
\hline 36 & 7 & 3 & - & & $\leftrightarrow$ (LE, grip) \\
\hline 37 & 29 & 18 & $\downarrow(14 \%)$ & $\uparrow(5 \%)$ & - \\
\hline
\end{tabular}

$\leftrightarrow$, no change; $\uparrow$, increase; $\downarrow$, decrease; grip, strength by hand-held dynamometry; LE, lower extremity strength, usually by isokinetic testing

Two studies were published evaluating the effect of HRT on measures of physical function, which is really the primary endpoint of clinical interest with regard to HRT and muscle. One study showed no effect of HRT on measured functional outcomes, although men on testosterone perceived a greater improvement in physical function than did men on placebo therapy ${ }^{32}$. Another study did demonstrate an improvement in physical function in those men receiving testosterone as part of rehabilitation after extended illness ${ }^{35}$.

\section{CHOICES OF THERAPY}

There are a number of testosterone therapy delivery systems, each associated with unique properties as well as adverse effects. The ideal agent is convenient, has predictable pharmacokinetics, is safe and inexpensive, and has low abuse potential ${ }^{47,48}$.

\section{ORAL}

Ninety-eight percent of the oral 17-a alkylated androgens (eg, fluoxymesterone, methyltestosterone, oxandrolone, and danazol) are completely metabolized by the liver in a first-pass effect, therefore decreasing their efficacy. Although available, these drugs may cause an increase in liver enzymes, cholestasis, peliosis of the liver, and liver tumors, and they should not be used to treat androgen deficiency ${ }^{48}$.

Testosterone has been esterified with undecanoate acid in position $17 \mathrm{a}$, avoiding hepatic metabolism by allowing absorption by the lymphatic system first. The half-life is only 1.5 hours, requiring multiple daily doses ( 3 to 4 times a day) to maintain maximal effect. Subnormal testosterone levels may occur during the day because of the amount available for absorption as well as of patient compliance in taking the medications. 


\section{PARENTERAL}

Intramuscular injections of longacting testosterone esters have been the mainstay of testosterone replacement for decades. The most common parenteral preparations are either testosterone enanthate or cypionate. Both have similar pharmacokinetics and are given as intramuscular injections of 200 to $300 \mathrm{mg}$ every 2 to 3 weeks. These injections result in supraphysiologic peak levels shortly after injection, followed by a gradual decline to nadir before the next injection. These wide and fluctuating ranges in testosterone levels often cause emotional lability. Though these injections are inexpensive, the adverse effects are the painful injection of this oil-based preparation and the wide fluctuations in mood.

\section{TRANSDERMAL}

As well as being inexpensive, transdermal therapy is a more physiological approach to testosterone replacement46,49. Transdermal patches are available in both scrotal and nonscrotal patches. Elemental testosterone is absorbed transdermally to produce serum testosterone levels within the normal range and to replicate the diurnal physiologic variation observed in young men. The hepatic first-pass metabolism is avoided, thereby limiting hepatotoxicity. Patches are available for bedtime use, with peak testosterone levels being achieved in the morning between 8:00 and 10:00 AM and a nadir prior to patch replacement. Evaluation of these patients should be carried out in the morning to determine the highest daily level of serum testosterone produced by the patch. The scrotal patch requires weekly shaving, and in individuals with small testes and inadequate scrotal skin, patches are difficult to apply. The nonscrotal testosterone patches applied to arm, torso, or thigh skin include Androderm ${ }^{\circledR}$ (SmithKline Beecham, Philadelphia) and Testoderm ${ }^{\circledR}$ TTS (Alza Corp., Vacaville, CA). The most common side effect of the dermal patches is dermatitis, often leading to the discontinuation of the use of the patch. Pretreatment of the skin area with $0.1 \%$ triamcinolone cream has proven to be effective in decreasing the adverse skin reactions ${ }^{50}$.

\section{TESTOSTERONE GEL}

Androgel $^{\circledast}$ (Unimed, Deerfield, IL) is a clear, colorless, hydroalcoholic gel containing $1 \%$ testosterone. A daily application on the shoulder, upper arm, or abdomen of $5 \mathrm{~g}$ of Androgel delivers $50 \mathrm{mg}$ of testosterone per day, with approximately $10 \%$ of the drug being absorbed during a 24-hour period. This gel has been shown to increase lean body mass, decrease body fat, and improve sexual function, mood, and muscle strength in hypogonadal men, regardless of age ${ }^{51,52}$. Since the active ingredient of this gel is not covered by a patch, there is a risk of transference of the testosterone to the partner. The application site must therefore be covered with clothes or washed before contact with another individual during the first several hours.

\section{MONITORING THE PATIENT}

During testosterone replacement, follow-up is important. The beneficial effects of therapy should be reviewed in terms of changes in the clinical manifestation of hypogonadism. Every 6 months, the efficacy of the treatment and its adverse effects should be reviewed. Total and free serum testosterone levels should be checked at 1 month, then every 6 to 12 months afterwards. Digital rectal examination and measurements of PSA should be performed prior to initiation of androgen replacement, at 3 and 6 months, and yearly thereafter. Any abnormality on repeat digital rectal examination, any elevation of PSA above the agespecific range, a significant increase in the velocity of PSA above the agespecific range, or a significant increase in the velocity of PSA $(>0.7 \mathrm{ng} / \mathrm{ml} /$ year) requires reassessment of the prostate gland with possible ultrasound and prostate needle biopsy.

Periodic measurements of hematocrit and total and HDL cholesterol are recommended (every 3 months). Osteoporotic elderly should be monitored for bone mineral density prior to therapy and 1 year thereafter.

For those individuals receiving transdermal patches or gel, testosterone levels should be evaluated at the time of peak levels in the early morning. Those receiving parenteral injections should have their testosterone measured at the peak, usually within the first week after the injection, as well as at the first nadir, just before the next injection. Older men with decreased metabolic clearance of testosterone may need to have their doses adjusted accordingly.

\section{CONCLUSION}

The use of testosterone in older men has become of increasing interest to both the medical and lay communities over the past decade. Even though the knowledge of the potential benefits and risks of male HRT has increased dramatically, there is still much that needs to be determined. Although HRT has resulted in increased bone mineral density, the impact on fracture risk is unknown. HRTcan lead to an increase in muscle mass and a decline in fat mass, but whether this translates into significant clinical changes in strength or function has not yet been proven. On the other hand, data continue to accumulate that HRT, with appropriate patient screening and monitoring, is relatively safe in the 
short term and that many of these early possible adverse effects can be managed. Well-controlled large multi- center trials need to be undertaken to determine whether or not HRT will increase the risk of developing or wors- ening cardiovascular or prostate disease.

\section{RESUMO}

PASQUALOTTO FF e col. - Riscos e benefícios da terapia de reposição hormonal em homens idosos. Rev. Hosp. Clin. Fac. Med. S. Paulo 59(1):32-38, 2004.

O uso da testosterona em homens idosos, conhecido como Terapia de Reposição Hormonal no homem ou Terapia de Reposição com Androgênios, têm aumentado o interesse para as comunidades médica e leiga na última década. Muito embora o conhecimento a respeito dos potenciais benefícios e riscos da Terapia de Reposição Hormonal nos homens tem aumentado dramaticamente, ainda existe muito que precisa ser determinado. Embora existam vários benefícios potenciais da Terapia de Reposição com Androgênios e dados clínicos relacionados com o uso de tal terapia, não existem ainda nenhum estudo contro- lado, randomizado e multicêntrico avaliando o uso de tal terapia. O objetivo deste artigo é revisar os aspectos atuais sobre os possíveis riscos e benefícios da Terapia de Reposição com Androgênios discutindo os estudos clínicos publicados sobre o assunto.

DESCRITORES: Testosterona. Androgênios. Hormônios. Idoso. Reposição.

\section{REFERENCES}

1. Gary A, Berlin JA, Mckinlay J et al. An examination of research design effects on the association of testosterone and male ageing: results of a meta-analysis. J Clin Endocrinol Metab 1994; 44: 671-84.

2. Vermeulen A. Clinical Review 24: Androgens in the aging male. J Clin Endocrinol Metab 1991; 73: 221-4.

3. Harman SM, Metter EJ, Tobin JD et al. Longitudinal effects of aging on serum total and free testosterone in healthy men. $\mathrm{J}$ Clin Endocrinol Metab 2001; 86: 724-31.

4. Tenover JL. Male hormone replacement therapy including "andropause". Endocrinol Metab Clin North Am 1998; 27: 969-87.

5. Bhasin S, Storer TW, Berman N et al. Testosterone replacement increases fat-free mass and muscle size in hypogonadal men. J Clin Endocrinol Metab 1997; 82: 407-413.

6. Bhasin S, Storer TW, Berman $\mathrm{N}$ et al. The effects of supraphysiologic doses of testosterone on muscle size and strength in normal men. N Engl J Med 1996; 335: 1-7.

7. Orwoll ES, Klein RF. Osteoporosis in men. Endocrin Review 1995; 16: 87-116.

8. Stanley HL, Schmitt BP, Poses RM et al. Does hypogonadism contribute to the occurrence of minimal trauma hip fracture in elderly men? J Am Geriatr Soc 1991; 39: 766-771.

9. Jackson JA, Riggs MW, Spiekerman AM. Testosterone deficiency as a risk factor for hip fractures in men: a case-control study. Am J Med Sci 1992; 304: 4-8.

10. Morley JE, Perry HM, Kaiser FE et al. Effects of testosterone replacement therapy in hypogonadal males: a preliminary study. J Am Geriatr Soc 1993; 41: 149-152.
11. Hayes JF. Editorial: Testosterone-fountain of youth or drug of abuse? J Clin Endocrinol Metab 2001; 85: 3020-3023.

12. Bonaccorsi AC. Andropausa: Insuficiência androgênica parcial do homem idoso. Uma Revisão. Arq Bras Endocrinol Metab 2001; 45: 123-133.

13. Morales A, Heaton JPW, Carson CC III. Andropause: a misnomer for a true clinical entity. J Urol 2000; 163: 705-712.

14. McClure DR. Androgen deficiency and the aging male: new urologic perspectives. Cur Urology Reports 2001; 2 (6): 453-459.

15. Flynn V, Hellstrom WJG. Androgen deficiency in the aging male: pathophysiology, diagnosis, and treatment alternatives. Cur Urology Reports 2001; 2 (6): 473-479.

16. Nieschlag E, Nieschlag S, Behre HM. Lifespan and testosterone. Nature 1993; 366: 215.

17. Phyllips GB, Pinkernell BH, Jing TY. The association of hypotestosteronemia with coronary artery disease in men. Arterioscler Thromb 1994; 14: 701-706.

18. Webb CM, Adamson DL, Dezeigler D et al. Effect of acute testosterone on myocardial ischemia in men with coronary artery disease. Am J Cardiol 1999; 83: 437-439.

19. Webb CM, MCneill JG, Hayward CS et al. Effects of testosterone on coronary vasomotor regulation in men with coronary heart disease. Circulation 1999; 100: 1690-1696.

20. Crook D - Androgens and the risk of cardiovascular disease. The Aging Male 2000; 3: 190-195.

21. Skakkeback NE, Bancroft J, Davidson JM et al. Androgen replacement with oral testosterone undecanoate in hypogonadal men: a double-blind controlled study. Clin Endocrinol 1981; 14: 49-61. 
22. Wang C, Alexander G, Berman $\mathrm{N}$ et al. Testosterone replacement therapy improves mood in hypogonadal men - clinical research center study. J Clin Endocrinol Metab 1996; 81: 35783583 .

23. Barret-Connor E, Von Muhlen DG, Kritz-Silverstein D. Bioavailable testosterone and depressed mood in older men the Rancho Bernardo Study. J Clin Endocrinol Metab 1999; 84: 573-577.

24. Hajjar RR, Kaiser RE, Morley JE. Outcomes of long-term testosterone replacement in older hypogonadal males: a retrospective analysis. J Clin Endocrinol Metab 1997; 82: 37933796.

25. Rabijewski M, Adamkiewicz M, Zgliczynski S. The influence of testosterone replacement therapy on well-being, bone mineral density and lipids in elderly men. Abstracts of the Second World Congress on the Aging Male, Geneva, Switzerland, 2000 [Abstract 009].

26. Tenover JS. Effects of testosterone supplementation in the aging male. J Clin Endocrinol Metab 1992; 75: 1092-1098.

27. Marin P, Holmang S, Gustafsson C, et al. Androgen treatment of abdominally obese men. Obesity res 1993; 1: 245-251.

28. Urban RJ, Bodenburg YH, Gilkison C et al. Testosterone administration to elderly men increases skeletal muscle strength and protein synthesis. Am J Physiol 1995; 269: E820-E826.

29. Sih R, Morley JE, Kaiser FE et al. Testosterone replacement in older hypogonadal men: a 12-month randomized controlled trial. J Clin Endocrinol Metab 1997; 82: 1661-1667.

30. Matsumoto AM, Sandlom RE, Schoene JA et al. Testosterone replacement in hypogonadal men: effects of obstructive sleep apnea, respiratory drives, and sleep. Clin Endocrinol 1985; 22: 713-721.

31. Santamaria JD, Prior JC, Fleetham JA. Reversible reproductive dysfunction in men with obstructive sleep apnea. Clin Endocrinol 1988; 28: 461-470.

32. Snyder PJ, Peachey H, Hannoush P et al. Effect of testosterone treatment on bone mineral density in men over 65 years of age. J Clin Endocrinol Metab 1999; 84: 1966-1972.

33. Krauss DJ, Taub HA, Lantiga LJ. Risks of blood changes in hypogonadal men treated with testosterone enanthate for erectile dysfunction. J Urol 1991; 146: 1566-1570.

34. Drinka PJ, Jochen AL, Cuisinier M et al. Polycythemia as a complication of testosterone replacement therapy in nursing home men with low testosterone levels. J Am Geriatr Soc 1995; 43: 899-901.

35. Bakhshi V, Elliott M, Gentili A et al. Testosterone improves rehabilitation outcomes in ill older men. J Am Geriatr Soc 2000; 48: 550-553.

36. Clague JE, Wu FCW, Horan MA. Difficulties in measuring the effect of testosterone replacement. Int J Androl 1999, 22: 261-265.

37. Katznelson L, Finkelstein JS, Schoenfeld DA. Increase in bone density and lean body mass during testosterone administration in men with acquired hypogonadism. J Clin Endocrinol Metab 1996; 81: 4358-4365.
38. Tenover JL. Experience with testosterone replacement in the elderly. May Clin Proc 2000; 75 (suppl): 19-25.

39. Behre HM. Testosterone therapy - effects on prostate and bone. Aging male 2000; 3: 196-202.

40. Shaneyfelt T, Husein R, Bubley G et al. Hormonal predictors of prostate cancer: a meta-analysis. J Clin Oncol 2000; 18: 847853.

41. Stepan JJ, Lachman M, Zverina J et al. Castrated men exhibit bone loss: effects of calcitonin treatment on biochemical indices of bone remodeling. J Clin Endocrinol Metab 1989; 69: 523527.

42. Goldray D, Weisman Y, Jaccard N et al. Decreased bone density in elderly men treated with the gonadotropin-releasing hormone agonist decapeptyl (D-Trp $\left.{ }^{6}-\mathrm{GnRH}\right)$. J Clin Endocrinol Metab 1993; 76: 288-290.

43. Behre HM, Kliesch S, Leifke E et al. Long-term effect of testosterone therapy on bone mineral density in hypogonadal men. J Clin Endocrinol Metab 1997; 82: 2386-2390.

44. Leifke E, Korner H-C, Link TM et al. Effects of testosterone replacement therapy on cortical and trabecular bone mineral density, vertebral body area, and paraspinal muscle area in hypogonadal men. Eur J Endocrinol 1998; 138: 51-58.

45. Reid IR, Wattie DJ, Evans MC et al. Testosterone therapy in glucocorticoid-treated men. Arch Intern Med 1996; 156: 11731177.

46. Arver S, Lonn L, Ekstrom U et al. The effects of physiological androgen replacement in aging diabetic men-a placebocontrolled study. Abstracts of the Second World Congress on the Aging Male, Geneva, Switzerland, 2000 [Abstract 008].

47. Zitzmann M, Nieschlag E. Hormone substitution in male hypogonadism. Mol Cell Endocrinol 2000, 161: 73-88.

48. Cunningham GR. Management of male aging: which testosterone replacement therapy should be used? Aging male 2000, 3: 203-209.

49. Parker S, Armitage M. Experience with transdermal testosterone replacement therapy for hypogonadal men. Clin Endocrin 1999, 50: 57-63.

50. Wilson DE, Kaidbey K, Boyke SC et al. Use of topical corticosteroid pretreatment to reduce the incidence and severity of skin reactions associated with testosterone transdermal therapy. Clin Ther 1998, 20: 299-306.

51. Swerdloff RS, Wang C, Cunningham G et al. Long-term pharmacokinetics of transdermal testosterone gel in hypogonadal men. J Clin Endocrinol Metab 2000, 85: 45004510 .

52. Wang C, Swerdloff RS, Iranmanesh A et al. Transdermal testosterone gel improves sexual function, mood, muscle strength, and body composition parameters in hypogonadal men. J Clin Endocrinol Metab 2000, 85: 2839-2853. 